\title{
Correction to: Spatiotemporal variation and source apportionment of organotin compounds in sediments in the Yangtze Estuary
}

Chunzhao Chen ${ }^{1,2}$, Ling Chen ${ }^{2,3}$, Rui Xue ${ }^{3}$, Qinghui Huang ${ }^{1,3}$, Lingling Wu $u^{1,2^{*}}$, Shufeng Ye ${ }^{4}$ and Wen Zhang ${ }^{5}$

\section{Correction to: Environ Sci Eur (2019) 31:24}

https://doi.org/10.1186/s12302-019-0207-z

The authors note a correction to the article [1]. Figure 1 of the original article is incomplete. Diaoyu Island, Chiwei $\mathrm{Yu}$ and the Dongsha Islands are missing. This article presents the corrected version of Fig. 1.

${ }^{*}$ Correspondence: wulingling@tongji.edu.cn; wulleco@hotmail.com

1 Key Laboratory of Yangtze River Water Environment of the Ministry

of Education, College of Environmental Science and Engineering, Tongji

University, Shanghai, China

Full list of author information is available at the end of the article 


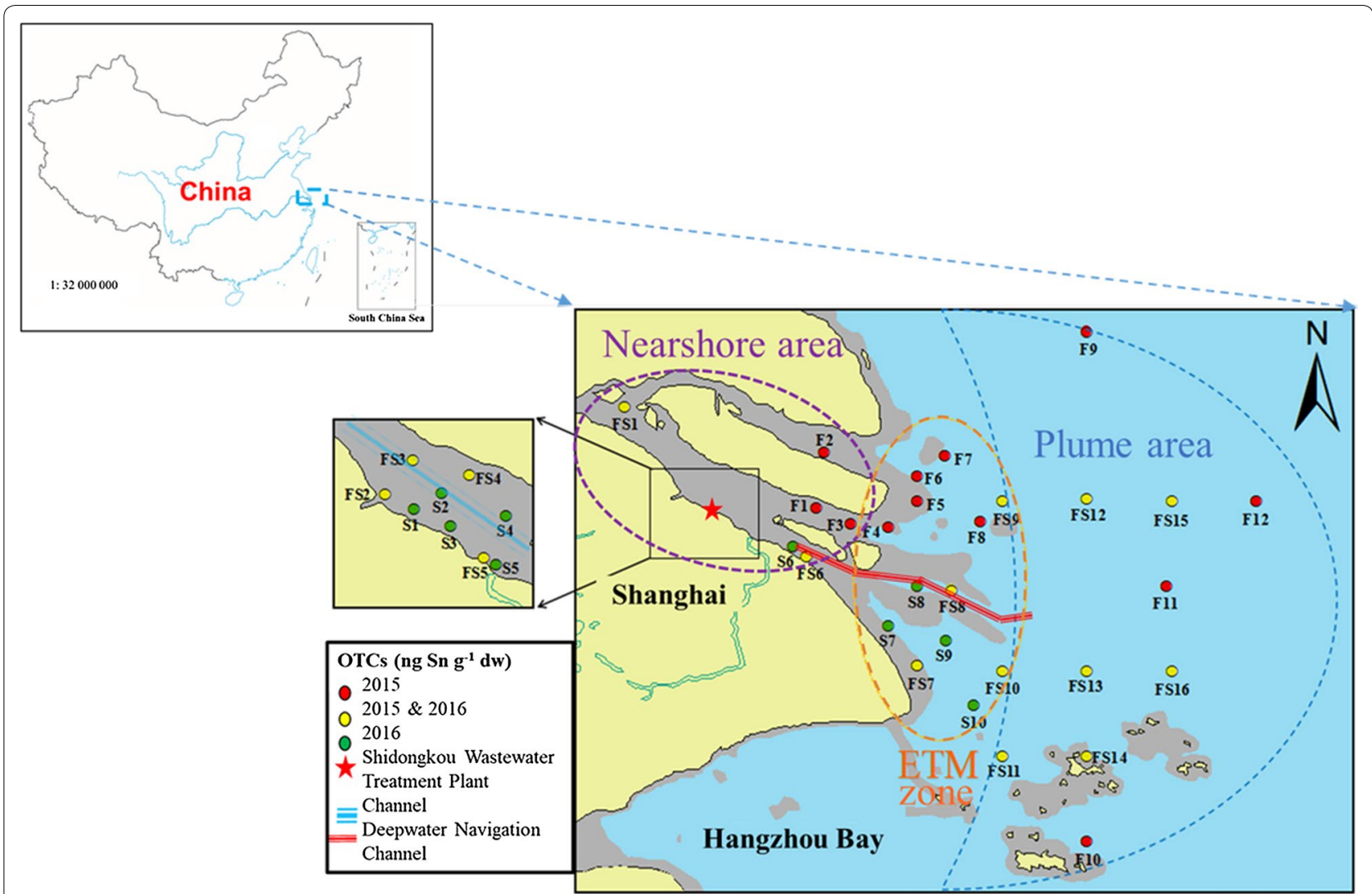

Fig. 1 Sampling sites in the Yangtze Estuary and nearby coastal areas. The pink dotted circle represented the Nearshore area, the orange dotted circle represented the Estuarine Turbidity Maxima (ETM) zone and the blue dotted sector represented the Plume zone

\section{Author details}

${ }^{1}$ Key Laboratory of Yangtze River Water Environment of the Ministry of Education, College of Environmental Science and Engineering, Tongji University, Shanghai, China. ${ }^{2}$ Shanghai Institute of Pollution Control and Ecological Security, Shanghai, China. ${ }^{3}$ State Key Laboratory of Pollution Control and Resource Reuse, College of Environmental Science and Engineering, Tongji University, Shanghai, China. ${ }^{4}$ East China Sea Environmental Monitoring Center, East China Sea Branch of the State Oceanic Administration, Shanghai, China. ${ }^{5}$ John A. Reif, Jr. Department of Civil and Environmental Engineering, New Jersey Institute of Technology, Newark, NJ, USA.

The original article can be found online at https://doi.org/10.1186/s1230 2-019-0207-z.

Published online: 16 July 2019

\section{Reference}

1. Chen C, Chen L, Xue R, Huang Q, Wu L, Ye S, Zhang W (2019) Spatiotemporal variation and source apportionment of organotin compounds in sediments in the Yangtze Estuary. Environ Sci Eur 31:24. https://doi. org/10.1186/s12302-019-0207-z

\section{Publisher's Note}

Springer Nature remains neutral with regard to jurisdictional claims in published maps and institutional affiliations. 